\title{
Fragmentation of Thinking Structure's Students to Solving the Problem of Application Definite Integral in Area
}

\author{
Kadek Adi Wibawa ${ }^{1,2}$, Toto Nusantara ${ }^{2}$, Subanji $^{2}$ \& I Nengah Parta ${ }^{2}$ \\ ${ }^{1}$ Universitas Mahasaraswati Denpasar, Indonesia \\ ${ }^{2}$ Universitas Negeri Malang, Indonesia \\ Correspondence: Kadek Adi Wibawa, Program Studi Pendidikan Matematika FKIP Universitas Mahasaraswati \\ Denpasar, Indonesia. E-mail: adi_math@yahoo.co.id
}

Received: October 24, 2016

Accepted: November 30, 2016

Online Published: April 29, 2017

doi:10.5539/ies.v10n5p48

URL: https://doi.org/10.5539/ies.v10n5p48

\begin{abstract}
This study aims to reveal the fragmentation of thinking structure's students in solving the problems of application definite integral in area. Fragmentation is a term on the computer (storage) that is highly relevant correlated with theoretical constructions that occur in the human brain (memory). Almost every student has a different way to construct a problem. That's very interesting to finding a process of thinking students. Researcher works in three cases. The findings of this study were two in every case, which the fragmentation whole construction and fragmentation construction pseudo. Data this study a full description and in-depth exploration of the students majoring in mathematics education since high school that has been learned about the material Integral course and the area.
\end{abstract}

Keywords: fragmentation of thinking structure, problems solving, application definite integral in area, whole construction, construction pseudo

\section{Introduction}

Various types of errors in solving the problems presented by researchers integral (Kiat, 2005; Yost 2009; Dorko, 2009; Serhan, 2015) but only limited studies conducted to identify any errors that occur. Further searches related to how to structure the thinking of students when experiencing difficulties and mistakes in solving a given problem has not been investigated further. Kiat (2005) revealed that there are three types of errors in solving integral problems, including 1) a conceptual error (conceptual errors), 2) procedural error (procedural errors), and 3) technical errors (technical errors). At the conceptual errors that occur, there are two findings, namely, students are not able to determine the area of the curve that cuts the X-axis and the second in the student's inability to obtain integral gradient function of a curve function. On procedural errors were also found two cases, including the failure to put a constant $\mathrm{c}$ when determining the indefinite integral or failure in manipulating the constant $\mathrm{c}$ when needed and second, students are confused in distinguishing derivatives and integrals. On a technical error, there are some cases, such as in coordinate geometry, kinematic, algebra, and trigonometry. The third type of error is that a finding by the Kiat (2005) can be categorized as a research analysis, which requires follow up in more depth. Search through the research process thinking into suggestions proposed in this study and remedial efforts can be done. More than this suggestion, researchers are interested in targeting students as the subject for a student teacher candidates who will be assigned to studying integral material and the complexity related to student understanding more fully integral material so that the findings could be more varied. Serhan (2015) also expressed their continued research is needed to investigate the students thought process when solving a given problem. Hence, writer interested to reveal the thought processes of students in problem solving application definite integral in area, which is one of the topics raised by the Kiat (2005).

One interesting phenomenon discovered and described by Kiat (2005) related to solving problems of students at Integral material. Kiat (2005) provides a single issue, namely the "Determine the area between the curve $y=x(x-4)$ and $\mathrm{X}$-axis from $x=0$ to $x=5$ " One subject of direct settlement, namely $\int_{0}^{5} x(x-$ 
4) $d x=\int_{0}^{5}\left(x^{2}-4 x\right) d x=\left[\frac{x^{3}}{3}-2 x^{2}\right]_{0}^{5}=\frac{125}{3}-50=-8 \frac{1}{3}$ unit. Completion is categorized Kiat (2005) as a conceptual error (conceptual errors), where students misunderstood the definite integral which should be understood as a broad concept of a region. When searching for more "depth" This fact may indicate a missing or disconnected relationship between the concept of definite integral as a comprehensive and definite integral as limit the Riemann of sum. This was confirmed by the results of interviews conducted by Kiat (2005), in which the subject says that:

\section{"... I think I just need to integrate the functions with the limits that have been granted"}

Answers from these students should be explored further related to statements made to find out what exactly the student become a problem and how to provide appropriate interventions so that understanding becomes true.

The integral concept is a very important concept in mathematics (Tall, 1975; Yost 2009; Varberg, Purcell, \& Rigdon, 2010). At least Varberg, Purcell, and Rigdon (2010) said that there are six usefulness of the concept of integral, such as to calculate the area of the field of price, volume rigid bodies (plates, discs, and rings), the volume of objects rotate (leather cylinder), the long curve of a field, and working fluid style, and are associated with the concept of chance and random variables. Tall (1975) adds that in order to be able to apply the necessary understanding of the integral concepts related to the concept of anti-derivatives and indefinite integrals. The second concept is a unity with the integral concept of course is very useful to help in resolving problems in other fields, such as physics and statistics. Although the concept of integral is very important to be understood by students, but the students' ability to solve problems is low.

Based on the theory of information processing, the data will be stored in the brain longer if already entered into long-term memory. Processes that occur are censored information or identified by sensory memory in a very short time (trillionth of a second) and then enter into short-term memory to be selected again according to the intensity of attention to acceptance of the idea that a person (Sternberg, 2012). If information is received intensity more attention, means that the information is often remembered, studied repeatedly, meaningful and memorable it from short-term memory the information will be forwarded to the long-term memory (forwarded mean that, the information will be creating a code of its own making it easier for someone for to call back). If information is weak or lacking the intensity of his attention, then it will disappear or not be passed on to the long-term memory. Such conditions can be analogy as conditions that occur in the computer system when a delay in calling the data. Computer slowness in the system is affected by the fragmentation of data in memory storage.

Fragmentation is defined as a condition in which a file that is placed on the storage media does not occupy sequentially sector. Fragmentation occurs when the operating system cannot allocate sufficient space on the storage sectors adjacent to store a complete file as a unit. This happens because often done deletion of files and then added back to the size and or file is not the same. Then what happens is the system will place the file in the first sector which is empty, and then trying to find the next sector that is not occupied by another file to put the rest of the parts of the file. If the sector, where the remainder of the file is very much part of the previous sector, then it is definitely his reading speed would be decreased. Examples of cases of fragmentation occur on the computer.

\begin{tabular}{|c|c|c|c|c|c|c|}
\hline (1) & A & \multicolumn{2}{|c|}{ B } & C & D & Free Space \\
\hline (2) & A & & & c & D & Free Space \\
\hline (3) & A & $\mathrm{E}$ & & C & D & Free Space \\
\hline (4) & A & $\mathrm{E}$ & $\mathrm{F}$ & C & D & $=$ Free Space \\
\hline
\end{tabular}

Figure 1. Illustration of fragmentation on the computer (sectors: storage space)

There are four cases on a hard drive that contains files A, B, C, D of the same size. Each occupies 6 sectors in the area of the disk (the first case of the image). In the second case, the file B is removed, so that there are sectors of the space between file A and file C. In a third case, the empty space between file A and file C, E placed file size 
smaller. It turns out there is empty space between file $\mathrm{E}$ and $\mathrm{C}$. The fourth case file, placed $\mathrm{F}$ file size larger than the empty space between the $\mathrm{E}$ and the file $\mathrm{C}$ file, and it turns out the remaining part of the file is placed in sector after sector occupied by D. file fragmentation occurs in the fourth case, where the F file located not in one sector (randomized), so this led to delays in making retrieval system. Cases that may occur as a continuation of the file $\mathrm{C}$ is deleted, so that there are holes sector which led to fragmentation in the files $\mathrm{F}$ getting worse.

Based on research conducted by Kiat (2005), Yost (2009), Dorko (2009) and Serhan (2015) on the application of problem solving definite integral in the area and analogies on computer-related fragmentation occurring, researchers interest to uncover how the fragmentation that occurred in the structure of thinking of students in solving problems in the application definite integral in area. Fragmentation can occur due to the construction pit (hole construction) and construction are apparent (pseudo construction). The term whole construction adapted from whole sector which occurred on a computer hard drive and construction pseudo adapted from non-full condition file in the storage space.

\section{Methodology}

\subsection{Research Design}

This study is a qualitative study that investigated a social phenomenon or a human problem (Creswell, 2007). The research findings are not obtained through statistical procedures. In this type of study, researchers created a complex picture, studying words, a detailed report on the views of the subject of research, and conduct studies in a natural situation. Qualitative methods are a research procedure that produces descriptive data in the form of written and spoken on the subject of research related to the behavior observed. Yin (2011) states that qualitative research to further highlight the process and meaning in the perspective of the subject.

\subsection{Participant}

The research was conducted at the State University of Malang in force 2014/2015 second semester student. In his vote of mathematics education student who has been studying the concept of integral since high school and pursues back at his lectures, is assumed to have complete structure of thought and depth so that the process of exploration conducted by researchers associated with fragmentation search structure thinking it would be more visible.

Subjects selected using purposive sampling. In purposive sampling, researchers deliberately chose to study people and places that are rich in information. Individuals that are rich in information are intended as an individual who indicated structure fragmented thinking and has good communication skills.

\subsection{Instruments}

Instruments in this study is the researchers themselves and assisted with job sheets and semi-structured interviews. As for the issue raised is

Table 1. Adoption instruments task sheet

\begin{tabular}{ll}
\hline Instruments task sheet Kiat (2005) & Instruments task sheet for this research \\
\hline Find the area between the curve $y=x(x-4)$ and the $x$-axis & Carilah luas daerah antara kurva $y=x(x-4)$ dan sumbu $X$, dari \\
from $x=0$ to $x=5$. & $x=0$ sampai $x=5$. \\
\hline
\end{tabular}

Structural problems that used to capture the fragmented structure student thinking in solving problems in the application of integral course the area is based on Polya step. As for the structure of the problem in question is: 


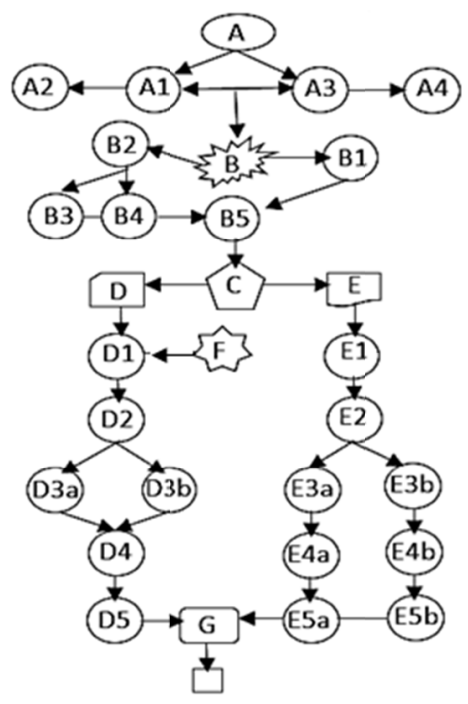

Figure 2. Structure of problem application definite integral in area

Table 2. Description of structure problem

\begin{tabular}{|c|c|}
\hline Coding & Explanation \\
\hline A & Understanding the problem of definite integral \\
\hline A1 & Understand asked the local area \\
\hline A2 & Understanding the area is positive \\
\hline $\mathrm{A} 3$ & Understanding the known boundaries \\
\hline A4 & Understanding the limits of the local area \\
\hline B & Devise a plan to draw the curve to determine the extent of the area \\
\hline $\mathrm{B} 1$ & Draw a curve $X-$ axis, $x=0, x=5$ \\
\hline B2 & Draw a curve $y=x(x-4)$ \\
\hline B3 & Determine the point of intersection \\
\hline B4 & Determining the cusp \\
\hline B5 & Making adjustments to the boundary of the curve \\
\hline $\mathrm{C}$ & Understanding the shape of two local area \\
\hline $\mathrm{D}$ & Calculate area 1: with a limit of integration $[0,4]$ \\
\hline D1 & Using the concept of integration to create model $L 1=-\int_{0}^{4} y d x$ \\
\hline $\mathrm{F}$ & Determining the value of the upper and lower elevation curve \\
\hline D2 & Changing the form $y$ \\
\hline D3a & Determine the result of integration of integration with direct \\
\hline $\mathrm{D} 3 \mathrm{~b}$ & Determine the outcome of integration with the theorem \\
\hline D4 & Substituting the limits to the equation \\
\hline D5 & Determine the result of area 1 \\
\hline E & Calculate area 2: with a limit of integration $[4,5]$ \\
\hline E1 & Using the concept of integration to create model $L 2=-\int_{4}^{5} y d x$ \\
\hline E2 & Changing the form $y$ \\
\hline E3a & Determine the result of integration of integration with direct \\
\hline $\mathrm{E} 3 \mathrm{~b}$ & Determine the outcome of integration with the theorem \\
\hline
\end{tabular}




\begin{tabular}{cl}
\hline E4a & Substituting the limits to the equation \\
\hline E4b & Substituting the limits to the equation \\
\hline E5b & Determine the result of area 1 \\
\hline & Octermine the result of area 1 \\
\hline & Occuring process of connecting consepts needed to solve the problems facing in the memory \\
\hline & Occuring process devise a plan in the memory \\
\hline
\end{tabular}

\section{Results}

In the present study found three variants of students in solving problems in the broad application of integral course area. 3 cases have been explored will be described by naming the first case on the subject 1 or S1, second cases on the subject 2 or S2, and third cases on the subject or S3.

\subsection{Case 1 on $\mathrm{S1}$}

S1 resolve a given problem without sketching graphs. S1 only imagine the extent of existing areas but not visualized in graphical form.

S1 started working on the given problem by looking at the curve and its limits. Then create a strategy or plan that this problem can be solved by using the integral rules. Here are excerpts of interviews conducted

$\mathrm{R} \quad$ : What did you think when You first read about this problem?

S1 : The first time I think sir are the curve and limits. Here was told to find the area bounded by the curve and these axes. So I imagine the Cartesian diagram. There is a curve defined by $x=0$ and $x=5$, so $x=0 x=5$ is a curve (pointing first step workmanship). Continue using the integral rules to calculate it.

$\mathrm{R} \quad$ : Why is integral?

S1 : Because I had studied ever before integral.

$\mathrm{S} 1$ can understand what is known and ask nicely. S1 is also trying to make a plan with integral necessarily apply to search the area. But the plan made by S1 is not complete, resulting in an error in determining the extent of the area and boundaries.

In settling, $\mathrm{S} 1$ is able to integrate properly means $\mathrm{S} 1$ has a good ability to apply the integral method is simple on a given problem.

$\mathrm{R} \quad$ : How you do it?

$\mathrm{S} 1$ : First is distributed then use the integral nature of the reduction. Then using indefinite integrals, first 
I integrated the function, then put boundaries.

$\mathrm{R} \quad$ : Then?

$\mathrm{S} 1$ : The area was nothing negative, so the answer is $25 / 3$.

$\mathrm{R}$ : Why change? Calculations turned into a $-25 / 3$ become 25/3.

S1 : Because as absolute.

From this, it appears that $\mathrm{S} 1$ does not do reflection and control over what is done. When determining the area properly, the calculations performed to produce a positive answer. In this case, S1 should be reflective thinking that something was not right with the calculation results are found. These conditions indicate the existence of the missing construction or the construction hole that led to the settlement process conducted unorganized or not connected properly. The following work is $\mathrm{S} 1$ in solving application problems in the area of definite integral.

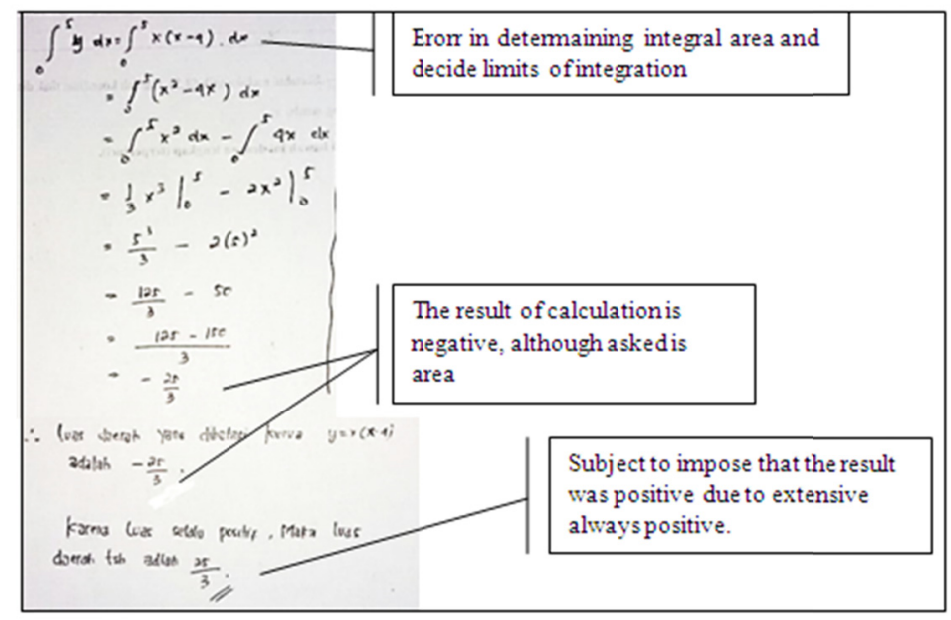

Figure 3. S1's results and analysis errors

Previous Kiat (2005) explained that the error that occurred is a conceptual error. But the findings in depth that do that, there is one hole construction and construction pseudo who made occur missing connections. This invention can be illustrated in the structure of thinking $\mathrm{S} 1$ in solving a given problem.

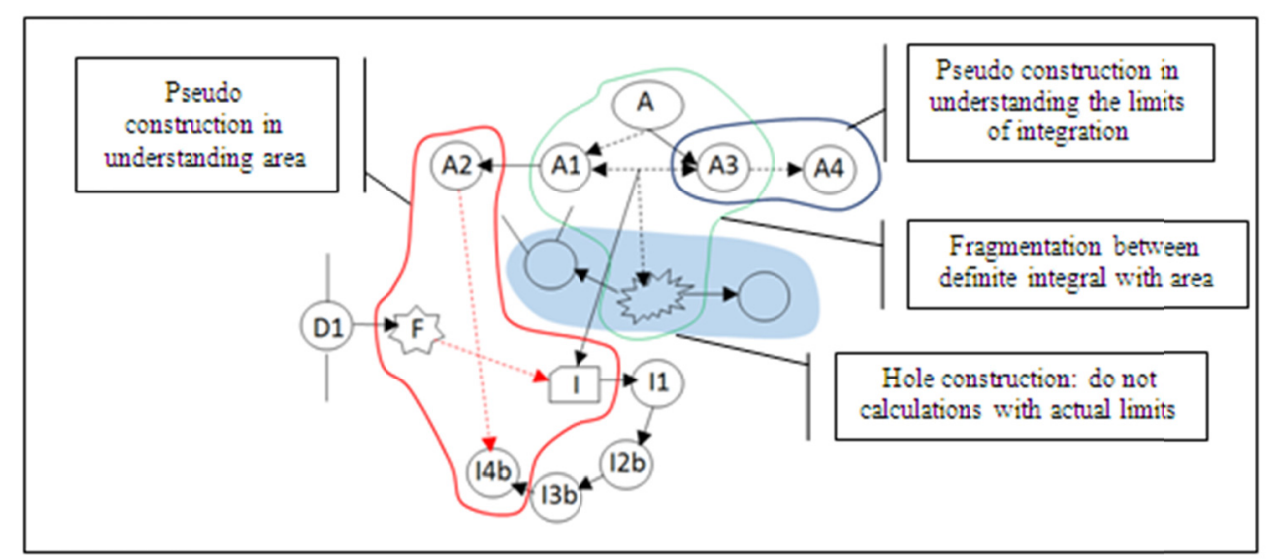

Figure 4. Structure of thinking S1 in solving problems of application definite integral in the area 
Table 3. Description of the structure of thinking S1

\begin{tabular}{|c|c|}
\hline Coding & Explanation \\
\hline I & Understanding the area with a limit of 0 to 5 \\
\hline I1 & Selecting Using the integral $L=\int_{0}^{5} y d x$ \\
\hline $\mathrm{I} 2 \mathrm{~b}$ & Implement measures selected by changing the shape $y$ to $x(x-4)=x^{2}-4 x$ \\
\hline $\mathrm{I} 3 \mathrm{~b}$ & Implement selected step by integrating $L=\int_{0}^{5} y d x$ to $\left[\frac{1}{3} x^{3}\right]_{0}^{5}-\left[2 x^{2}\right]_{0}^{5}$ \\
\hline $\mathrm{I} 4 \mathrm{~b}$ & Implement selected step by substituting the limits of 0 to 5 to $x$, obtained $\frac{5^{3}}{3}-25^{2}=\frac{125}{3}-50=\frac{125-150}{3}=-\frac{25}{3}$ \\
\hline D1 & Understanding the area with a limit of 0 to 4 \\
\hline $\mathrm{F}$ & Understanding the area below the $\mathrm{x}$-axis is negative for upper curve - the curve below $L 1=\int_{0}^{4}(0-y) d x$ \\
\hline \multirow[t]{5}{*}{ Symbol } & Explanation \\
\hline & Fragmentation pseudo construction: the boundaries of the area of integration are not seen as the side of the area being searched. \\
\hline & $\begin{array}{l}\text { Fragmentation hole construction: not necessarily interlinked concepts integral to the area because there are holes in the area of } \\
\text { integration which construction has not been determined }\end{array}$ \\
\hline & $\begin{array}{l}\text { Fragmentation pseudo construction: a positive sign in the area simply understood as "necessity" and not based on the high } \\
\text { concept of an area of integration }\end{array}$ \\
\hline & $\begin{array}{l}\text { Hole construction: when a student's inability to understand the area as an integral course (not captured the area as an integral } \\
\text { course) }\end{array}$ \\
\hline
\end{tabular}

\subsection{Case 2 on $S 2$}

S2 solve the problem given by sketching graphs, but the sketch made of no help in finding the right solution. From sketches made S2 led to a new confusion resulting S2 does not solve the problem to find the answers.

S2 initiate settlement by drawing a curve in the Cartesian diagram, search for the point of intersection and determine the cusp. Then S2 thought to determine the extent of areas with known boundaries. Here is an interview with a researcher $\mathrm{S} 2$.

$\mathrm{R}$ : What did you think when you first face this matter, resolving this problem?

$\mathrm{S} 2$ : We were told to finding restricted area of this curve. In the $X$-axis, $x=0$ and $x=5$. First I think, illustrates the curve, meet like this (pointing to the image created on the task sheet). That cut $X-$ axis $=0$ and $x=4$ continues its peak point at $(2,-4)$. I continue to be confused here, the limit. Maybe if the $X$-axis is that I know the boundaries to sign less than or greater than. If it was just like this, (pointing drawings made on the assignment sheet), LHA, I confused this or this (pointing image/area curve).

$\mathrm{R}:$ Why did you think that we should draw?

$\mathrm{S} 2$ : I want to know first the shape. Continue after know its shape, it limits like this, keeps me confused. If the limit is usually, less than or more than, like, the shape inequalities. But after I picture shuttlecock shape like this. More confused. Areas that fulfill that which, area that meets the where deciding.

S2 seemed confused when determining the extent of the area on a chart created sketches. S2 think that it should be the limits of the known form of inequality. Here is a sketch of the graph of the results of S2. 


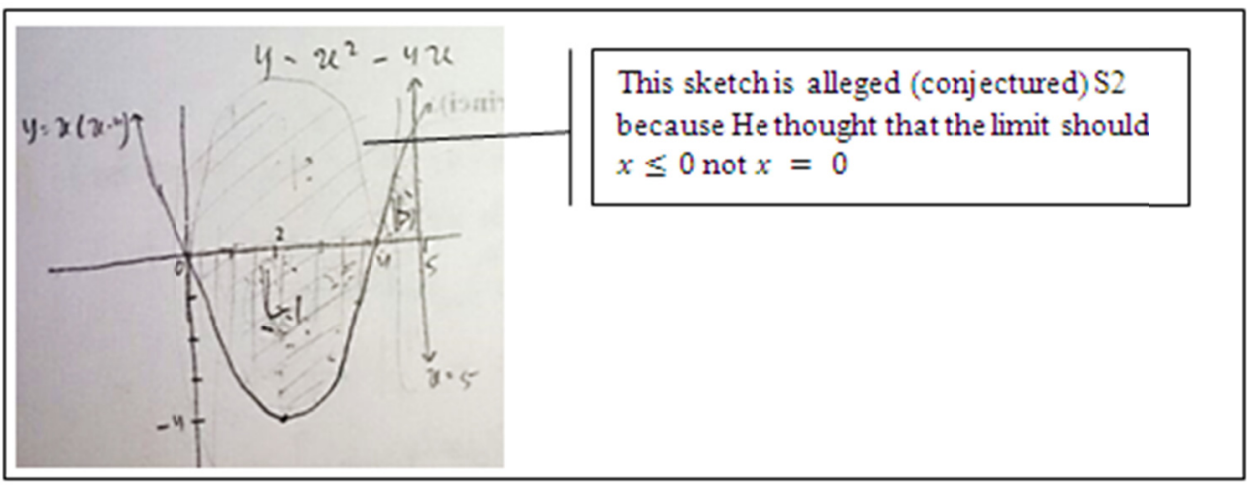

Figure 5. Sketch the graph by S2

Hole construction going on S2 is the inability to see the limits of the given whole and not separate from one boundary to the other boundary. Fragmentation happens is between the area of integration with the limits of integration which is due to the construction pit at S2 understanding of the limits of the given problem. Having explored further, S2 remains on its conviction that this problem cannot be solved because of the limits given in the problem is unclear or inconsistent with the understanding that $\mathrm{S} 2$ had over the years.

The thought process S2 in solving application problems certainly integral in solving the area can be represented in the form of structure think S2 by step Polya. The fragmentation of thinking on the structure S2 will be visible through this representation.

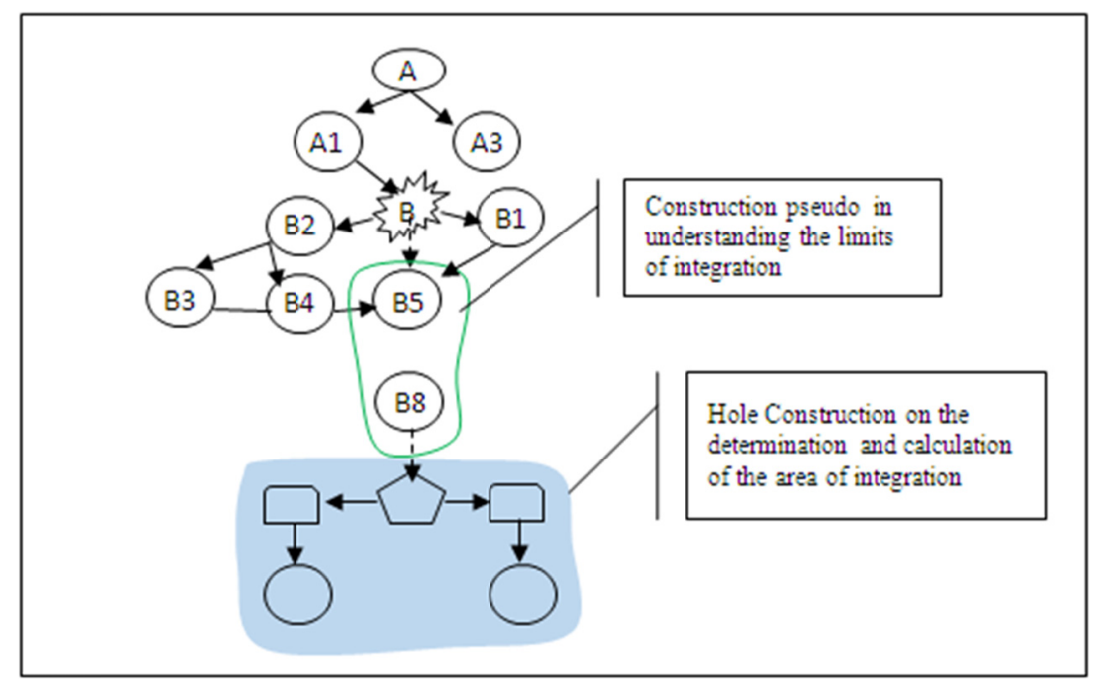

Figure 6. Structure of thinking S2

Table 4. Description of the structure of thinking S2

\begin{tabular}{ll}
\hline Coding & Explanation \\
\hline B8 & Understanding the limits of integration that should be in the form of inequality so that the area can be determined extents \\
\hline
\end{tabular}

\subsection{Case 3 on $\mathrm{S} 3$}

S3 solve the problem given by sketching graphs, but the sketches are made are not put to good use in determining the boundaries of integration and determine the area of integration. S3 is not able to tie the sketch made by settling.

S3 started work by associating the given problem ever faced with problems when high school. Here are the results of exploration of the S3 


\section{$\mathrm{R}$ : What did you think when you first resolving this problem?}

S3 : It's a lesson grade 2 SMA (Senior High School). I kept forgetting the fact, how to do things this way. Then I think about it, if not wrong, that, just later than demarcated, this limits the $x$-axis, $x=0$, $x=5$ and $y=x(x-4)$. I kept looking for the points. It turns out I found the area is, the interval of 0 to 4. Actuall, I was forgotten, but my remain, if under the $x$-axis the result is the minus.

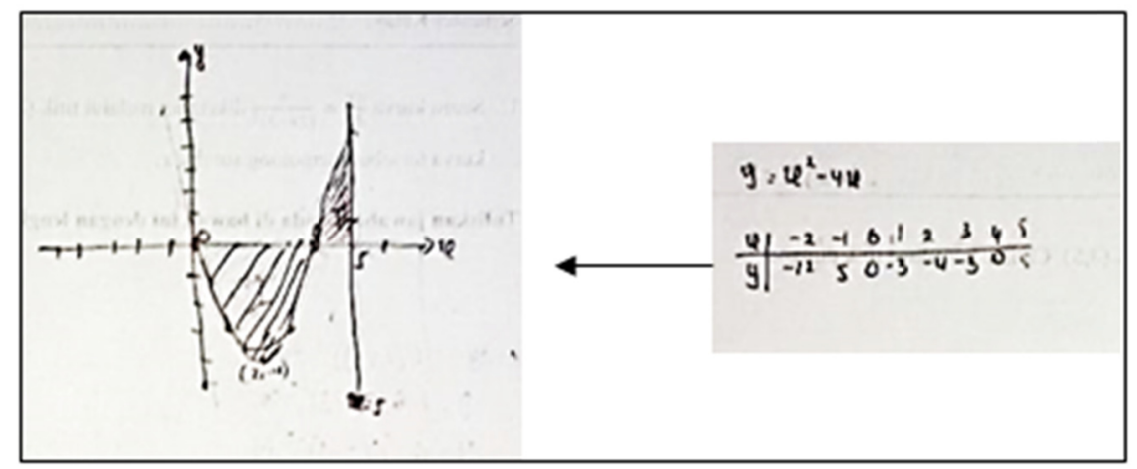

Figure 7. Sketch a graph created by S3

Note. Shading extents area shown in the image above was performed S3 after some reflection. Previously, do not shade the area extents. S3 only sketched the graph $y=x(x-4)$ and $x=5$.

Table created S3 help in sketching the graph $y=x(x-4)$. However, the sketch graphics that made not used S3 to determine the extent of the area. S3 see that $f(x)$ exists, ie $f(x)=x(x-4)$ and the boundaries can be determined, namely: $x=0$ and $x=4$. With this understanding, S3 directly perform calculations of integration. Here's an interview related to a table created by $\mathrm{S} 3$

$\mathrm{R}$ : What is this table?

S3 : To search for the points of the function $x(x-4)$.

$\mathrm{R}$ : So after may dots? Which is $(-2,-12)$ ?

S3: This pack.. (pointing Cartesian diagram) eh ehh.. i ranging from (0.0) pack. Because the boundries is $x=0$, so I started from 0 . Continues (1, -3), 2 to $-4,4$ to 0 .

$\mathrm{R}:$ Why is revealed to turn here?

$\mathrm{S} 3$ : As already revealed to the dots, so it's impossible for the straight wrote pack. Just connect the dots.

$\mathrm{R}$ : what is $(2,-4)$ in the curve $y=x(x-4)$ ?

$\mathrm{S} 3$ : The apex of the curve.

Based on the explanation S3 associated with the table is created, there is a drawback particularly related to determining the inflection point of a curve. In determining the point $(2,-4)$ as the apex, S3 just understand that the graphs of quadratic equations are not straight, to turn, means that $\mathrm{S} 3$ must choose one point among points specified as the extreme point. There is an understanding that pseudo or vague in determining this.

Furthermore S3 implement a plan created to calculate the area with the functions and limits specified. Here is the completion of the S3. 


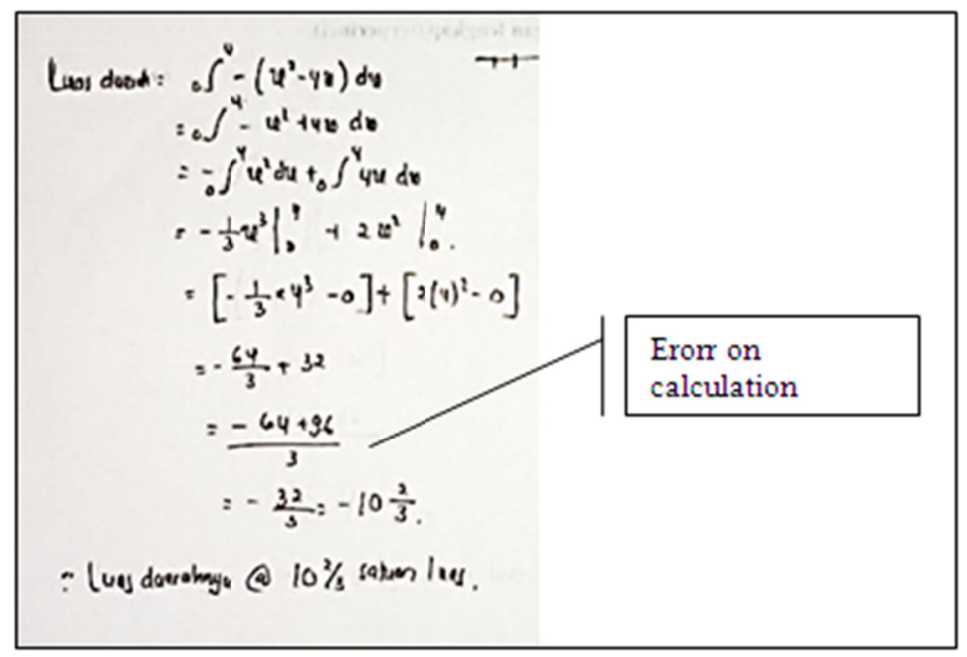

Figure 8. Integral calculations performed by S3

Completion conducted by S3 indicates that the graph made unhelpful S3 to understand the problem well. Precisely strengthen S3 graphics made in determining the limits of integration from 0 to 4 . In reflection not done by $\mathrm{S} 3$ after finding the final result is negative. Here's an interview conducted by researchers:

\section{$\mathrm{R}$ : Why the minus?}

$\mathrm{S} 3$ : Because under the $X$ - axis

$\mathrm{R}$ : There is a rule not? Why is it so negative?

S3 : Yaa Mr. Well.. that's because under the $x$ - axis

Snapshot This statement shows that the area of integration of concern S3 is just the area under the $x$-axis with boundary $x=0$ and $x=4$. S3 also understand that the reason for the negative result because under the curve, whereas the context of a given problem, is to determine the area. Which, curve limiting the area in question is $y=0$ or the $x$-axis and $y=x(x-4)$.

S3 explained his understanding regarding the relationship between the area with definite integral. Which, S3 does not care about negative or positive results of the calculations, is definitely when requested is the area, the end result is positive. Following the results of the interview:

$\mathrm{R}$ : What is the problem?

\section{$\mathrm{S} 3$ : find the area}

\section{$\mathrm{R}$ : After the drawing, find a local area?}

S3: Yes. The Area is using the integral. That is already known that the limit of 0 to 4. Keep the formula is staying put. It's a function just one. So direct, the direct use $\int f(x) d x$. Since this is below the $x$-axis so minus. (Communicating the work process)

$\mathrm{R}$ : What are the results?

S3: The result was negative. But the area was not affected by the negative positive. So to conclude, the dot-dot area is how unit area.

The thought process S3 in solving problems of application definite integral in the area can be represented in the form of the structure of thinking S3 by Polya's step. The fragmentation of thought on the S3 structure would look through these representations. 


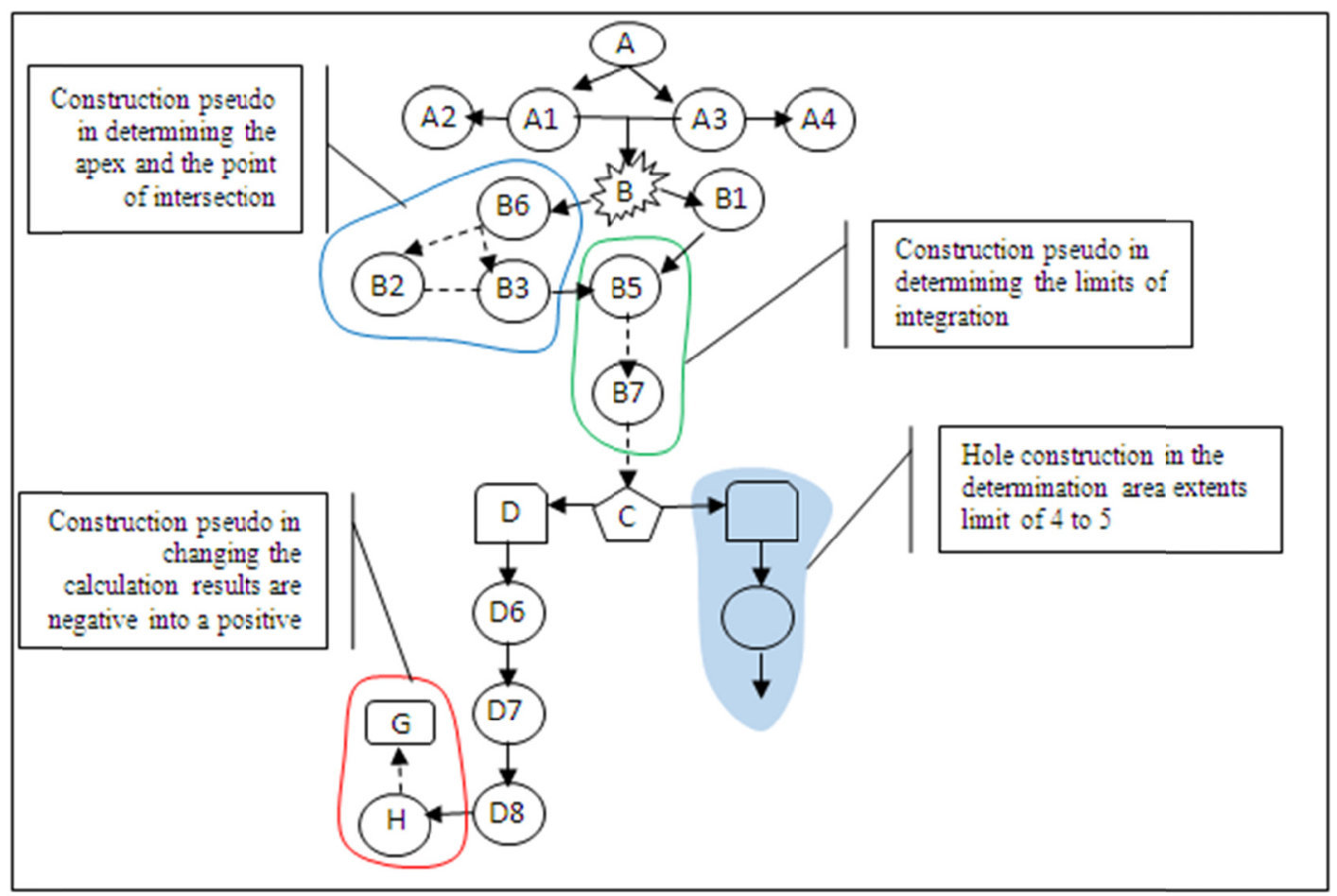

Figure 9. Structure of thinking S3

Table 5. Description of the structure of thinking S3

\begin{tabular}{|c|c|}
\hline Coding & Explanation \\
\hline B6 & Make a table to determine the graph of the function $y=x(x-4)$ \\
\hline B7 & Determining the limits of integration \\
\hline $\mathrm{H}$ & $\begin{array}{l}\text { Changing the calculation results are negative to positive, on the grounds that the area in question is an error when terlatak on } \\
\text { arithmetic calculation. }\end{array}$ \\
\hline
\end{tabular}

\section{Discussion and Conclusion}

Gagne (in Tall \& Razali, 1993) said that there are four phases of learning: capture phase, acquisition phase, storage phase and the retrieval phase (remember). Tall and Razali (1993), for students who are thinking lower very often experience difficulties at the fourth stage, which is taking information that has been learned. This causes students often incorrectly construct a concept and solve their problems. Preliminary observations conducted by researchers at the student actually found the fact that the more developed, where students choose courses of mathematics education as a concentration is still experiencing an error in solving a given problem. The complexity of the material and the mathematical ideas that are owned or had experienced did not make the students more rich ability to solve problems.

In solving these problems, there are four main ideas and sequences that must be understood and considered by the student (subject). 1) Definite integral as an area; relating to the area extents, curves, and limit 2) Representation functions in geometry; relating to the Cartesian diagram, function rules, the point of intersection and the apex point, 3) area is positive; related to the difference between the upper and lower curve, and 4) definite integral as an integral Riemann; with regard to rules of functions, limits, and procedures of integration that can be used. The pattern of student thinking structure in solving the given issue, is: 


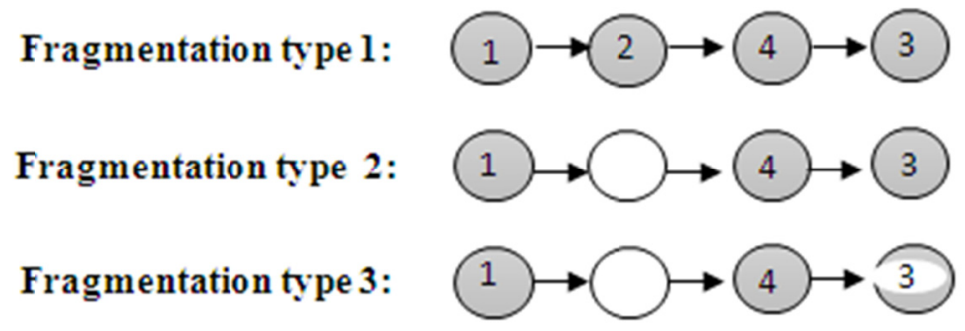

Figure 10. Types of fragmentation structure of thinking

Fragmentation type 1, illustrates that there are ideas that are not sequential between 2 , 4, and ideas 3 . After thinking subject integral Riemann and representation functions in geometry, the subject immediately think about what procedures can be used to solve problems encountered. When the subject found the calculation result is negative, the subject of new thinking about the context of the issues regarding the area. This happens on S2 and S3. Fragmentation type 2, describes the construction holes in the idea and the idea randomized 2 between the idea of 1,4 and 3 . The subject did not think about the determination of the representation of functions in geometry, a subject only see that in determining the area of the integral Riemann, departing from the rule function already known, and the limits that have been provided. Subject proceeds with necessary procedures on the definite integral usable. After that, it occurred in the area that should be positive. This occurs in S1. Fragmentation type 3, describes the whole construction, the structure of thinking randomized (non-sequential), and their construction pseudo. Construction pseudo happens when the subject justify that the area is positive because it is like that, "the area should be positive, so negative sign calculation results can be directly replaced with a positive sign". This is a construction pseudo, where the subject is correct in giving answers that the area should be positive, but the justification is not right, just a superficial thinking and do not have a solid foundation. It also happens to $\mathrm{S} 3$.

Based on the above explanation, the researchers thought the structure to categorize their fragmentation into three types, namely fragmentation non-sequential-error, fragmentation whole construction, and fragmentation construction pseudo. Behavior thinking non-sequential or sequential occurred beginning with the student's understanding incomplete on one or more concepts, so that the process of reflection that is done after finding an outcome would be very weak. The behavior of the whole construction can be seen from the absence of construction that thought is written by students in terms of solving a given problem which should have a good understanding of the construction, strategy, and troubleshooting procedures exist or thought. And their behavior can be observed construction pseudo of the construction there or understanding, strategies, and or procedures exist (think and do), but the justification for that construction is weak or absent, the student answers more on the word "essentially like this..." "My remained is like this, but they do not know is true or not."

Such research needs to be carried out further searches related to the process of fragmentation structure of thinking in students, especially in the context of non-routine problems. And also it's necessary to attempt repairs or arrangement to allow students to perform defragmentation structure of thinking. In order for the structure to think a student can survive in a very long time, it is necessary to also do a treatment to ensure that the way of thinking that is done is correct.

\section{References}

Creswell, J. W. (2007). Qualitative Inquiry and Research Design. Choosing among Five Approaches (2nd ed.). Thousand Oaks, CA: Sage.

Dorko, A. (2009). Calculus Student' Understanding of Area and Volume in Non-Calculus Context (Thesis, University of Maine). Retrieved from http://umaine.edu/center/files/2011/10/DorkoThesis.pdf

Kiat, S. E. (2005). Analysis of Student' Difficulties in Solving Integration Problems. The Mathematics Educator, 9(1), 39-59. Retrieved from http://math.nie.edu.sg/ame/matheduc/tme/tmeV9_1/Seah\%20EK.pdf

Serhan, D. (2015). Students' Understanding of the Definite Integral Concept. International Journal of Research in Education and Science (IJRES), 1(1), 84-88. https://doi.org/10.21890/ijres.00515

Sternberg, R. J., \& Sternberg, K. (2012). Cognitive Psychology (6th ed.). USA: Wadsworth Cengage Learning.

Tall, D. (1975). A Long-Term Learning Schema for Calculus and Analysis. Mathematical Education for Teaching. Retrieved from http://homepages.warwick.ac.uk/staff/David.Tall/pdfs/dot1975a-long-term-learning.pdf 
Tall, D., \& Razali, M. R. (1993). Diagnosing Student' Difficulties in Learning Mathematics. International Journal of Mathematics Education Science, 24(2), 209-222. https://doi.org/10.1080/0020739930240206

Varberg, Purcell, \& Rigdon (2010). Kalkulus Edisi Kesembilan Jilid I. Terjemahan Susila, I. N. Jakarta: Erlangga.

Yin, R. K. (2011). Qualitative Research from Start to Finish. New York: The Guilford Press.

Yost, D. (2009). Integration: Reversing Traditional Pedagogy. Australian Senior Mathematics Journal, 22, 37-40. Retrieved from http://files.eric.ed.gov/fulltext/EJ819412.pdf

\section{Copyrights}

Copyright for this article is retained by the author(s), with first publication rights granted to the journal.

This is an open-access article distributed under the terms and conditions of the Creative Commons Attribution license (http://creativecommons.org/licenses/by/4.0/). 